\title{
Clinical factors affecting pathological fracture and healing of unicameral bone cysts
}

\author{
Hiroshi Urakawa ${ }^{1 *}$, Satoshi Tsukushi ${ }^{1}$, Kozo Hosono ${ }^{2}$, Hideshi Sugiura ${ }^{3}$, Kenji Yamada ${ }^{2}$, Yoshihisa Yamada ${ }^{4}$ \\ Eiji Kozawa ${ }^{1}$, Eisuke Arai ${ }^{1}$, Naohisa Futamura ${ }^{1}$, Naoki Ishiguro ${ }^{1}$ and Yoshihiro Nishida $^{1}$
}

\begin{abstract}
Background: Unicameral bone cyst (UBC) is the most common benign lytic bone lesion seen in children. The aim of this study is to investigate clinical factors affecting pathological fracture and healing of UBC.

Methods: We retrospectively reviewed 155 UBC patients who consulted Nagoya musculoskeletal oncology group hospitals in Japan. Sixty of the 155 patients had pathological fracture at presentation. Of 141 patients with follow-up periods exceeding 6 months, 77 were followed conservatively and 64 treated by surgery.

Results: The fracture risk was significantly higher in the humerus than other bones. In multivariate analysis, ballooning of bone, cyst in long bone, male sex, thin cortical thickness and multilocular cyst were significant adverse prognostic factors for pathological fractures at presentation. The healing rates were $30 \%$ and $83 \%$ with observation and surgery, respectively. Multivariate analysis revealed that fracture at presentation and history of biopsy were good prognostic factors for healing of UBC in patients under observation.

Conclusion: The present results suggest that mechanical disruption of UBC such as fracture and biopsy promotes healing, and thus watchful waiting is indicated in these patients, whereas patients with poor prognostic factors for fractures should be considered for surgery.
\end{abstract}

Keywords: Unicameral bone cyst, Pathological fracture, Healing, Prognosis, Clinical factors

\section{Background}

Unicameral bone cyst (UBC) is a benign bone lesion that affects children and young persons. This lesion has been reported together with aneurysmal bone cyst $(\mathrm{ABC})$ [1]. USP6 and CDH11 oncogenes were reported to be identified in primary $A B C[2]$, whereas the etiology of $U B C$ remains unclear. Various pathogenetic mechanisms have been proposed including mechanical trauma, inflammation, and venous obstruction in the bone $[3,4]$.

Because of the benign nature of UBC, the primary purpose of treatment is prevention of pathological fracture. Some reports have identified risk factors of pathological fractures. Previous reports indicated that high cyst index (area of the cyst/diaphysis diameter ${ }^{2}$ ) [5], high percent of bone occupied by the cyst in the transverse plane [6], thin cortical thickness [7], and location in the upper limb [8]

\footnotetext{
* Correspondence: urakawa@med.nagoya-u.ac.jp

${ }^{1}$ Department of Orthopedic Surgery, Nagoya University Graduate School and School of Medicine, 65 Tsurumai, Showa-ku, Nagoya, Aichi 466-8550, Japan Full list of author information is available at the end of the article
}

significantly increased the incidence of pathological fractures. Although paradoxical, cyst healing was associated with the occurrence of pathological fractures. Previous reports showed that UBC healed spontaneously after fractures $[6,9]$. Other reports demonstrated that fracture [10], small cyst volume [10], cyst index [5], and long distance from the growth plate [11] significantly increased the rate of UBC healing after treatment.

The first aim of this study was to identify the risk factors associated with the occurrence of pathological fracture, since it is important to anticipate the risk of this complication when deciding on strategies of UBC treatment. The second purpose was to identify the factors influencing UBC healing, to aid in deciding treatment for patients with UBC.

\section{Methods \\ UBC patients who consulted 4 Nagoya musculoskeletal on- cology group hospitals (Nagoya University Hospital, Aichi Cancer Center Hospital, Aichi Cancer Center Aichi Hos- pital, Nagoya Memorial Hospital) in Japan between January}


1988 and February $2011(\mathrm{n}=168)$ were collected. Thirteen patients were not suitable for the purposes of this study because of a lack of clinical records. One hundred fifty-five consecutive patients with UBC were retrospectively reviewed. As our treatment strategy of UBC, a biopsy was performed in patients in whom the possibility of other conditions was suspected $(n=30)$. Pathological fractures were treated as a rule with immobilization. Surgical treatments were carried out in symptomatic patients, cases predisposed to fracture, or for bone cysts located in the proximal femur in which dislocation of the fracture, coxa vera, and avascular necrosis of the femoral head were major concerns $[12,13]$.

Baseline patient characteristics are summarized in Table 1. All 155 patients selected were evaluable for pathological fracture at presentation, and 141 patients with follow-up periods over 6 months were evaluable for UBC healing.

Characteristics and treatments of 141 patients included in evaluation of healing are summarized in Table 2. The median follow up period was 28.7 (range 6.0-178.8) months. Seventy-seven cases were observed and 64 cases were treated by surgery. In patients of surgery, many of young patients with UBC were treated by cannulated screws, but various treatment methods were used for these patients. A biopsy was performed in 30 of 141 patients. Healing of the lesion was defined as healing of over $50 \%$ of the cyst area on X-ray at the last follow up (Figure 1).

Table 1 Baseline characteristics of all patients $(n=155)$

\begin{tabular}{lc}
\hline Characteristics & Value (range) or No. of patients (\%) \\
\hline Sex & $101(65 \%)$ \\
Male & $54(35 \%)$ \\
Female & \\
Age, years & $14(2-58)$ \\
Median (range) & \\
Size, cm & $4.0(0.9-25.0)$ \\
Median (range) & \\
Anatomic site & $55(35 \%)$ \\
Humerus & $41(26 \%)$ \\
Calcaneus & $35(23 \%)$ \\
Femur & $10(6 \%)$ \\
Pelvis & $5(3 \%)$ \\
Tibia & $5(3 \%)$ \\
Fibula & $4(3 \%)$ \\
Others & \\
Pathological fracture & $60(39 \%)$ \\
Yes & $95(61 \%)$ \\
No &
\end{tabular}

Table 2 Characteristics and treatments of patients included in evaluation for healing $(n=141)$

\begin{tabular}{lc}
$\begin{array}{l}\text { Characteristics and } \\
\text { treatments }\end{array}$ & $\begin{array}{c}\text { Value (range) or No. of patients } \\
(\%)\end{array}$ \\
\hline Sex & $90(64 \%)$ \\
Male & $51(36 \%)$ \\
Female & \\
Age, years & $14(2-58)$ \\
Medize, cm (range) $\quad$ Median (range) & \\
Anatomic site & $4.0(0.9-25.0)$ \\
$\quad$ Humerus & \\
Calcaneus & $54(38 \%)$ \\
Femur & $35(25 \%)$ \\
Pelvis & $31(22 \%)$ \\
Tibia & $9(6 \%)$ \\
Fibula & $5(4 \%)$ \\
Others & $5(4 \%)$
\end{tabular}

Pathological fracture at first visit

$\begin{array}{ll}\text { Yes } & 59(42 \%) \\ \text { No } & 82(58 \%)\end{array}$

Biopsy

$\begin{array}{cc}\text { Open } & 25(18 \%) \\ \text { Needle } & 5(4 \%) \\ \text { None } & 111(79 \%)\end{array}$

Treatments

$\begin{array}{ll}\text { Observation } & 77(55 \%) \\ \text { Surgery } & 64(45 \%)\end{array}$

Operative procedure at first time

$\begin{array}{cc}\text { Cannulated screws } & 35(55 \%) \\ \text { Curettage and graft } & 12(19 \%) \\ \text { Curettage } & 3(5 \%) \\ \text { Drilling } & 3(5 \%) \\ \text { Others } & 11(17 \%)\end{array}$

No. of surgeries

$\begin{array}{cc}\text { Single } & 50(78 \%) \\ \text { Multiple } & 14(22 \%)\end{array}$

Follow-up, months

Median (range)

$28.7(6.0-178.8)$

Clinical data were collected from the patient's clinical records. Chi-square test or Fisher's exact test and multiple logistic regression were used to analyze the correlation of various clinical factors with fracture at presentation or healing of UBC. Clinical factors such as sex, age $(\geqq 20,<20)$, sites (long bone or not) (specific bone or not), diameter $(\geqq 5 \mathrm{~cm},<5 \mathrm{~cm})$, multilocular, ballooning of bone, and 


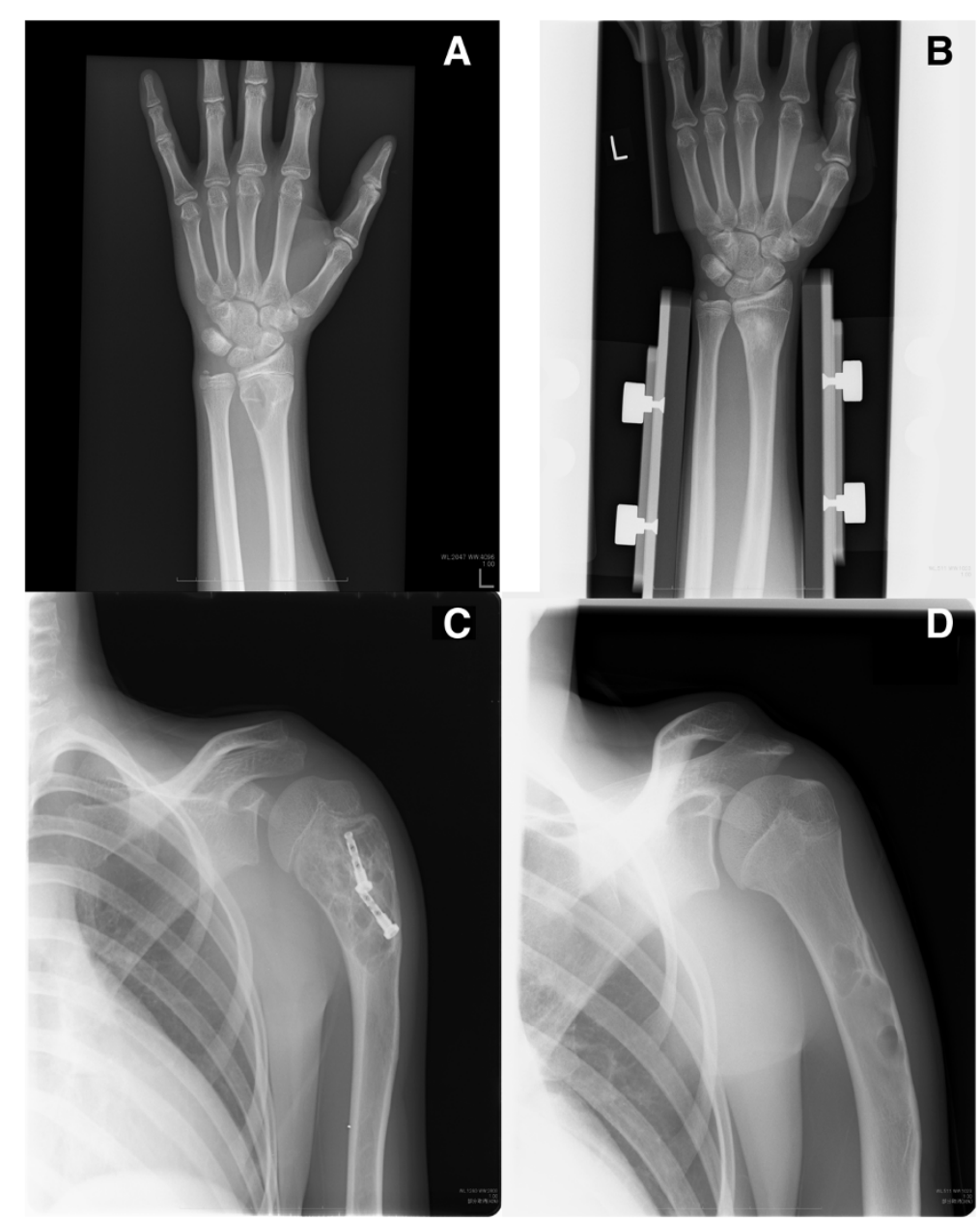

Figure 1 Healing of UBC. Fifteen-year-old male of UBC in his left distal radius: Anteroposterior radiograph at his first presentation (A) and 12 months later (B). He had a pathological fracture at first visit and complete healing was observed after observation. Ten-year-old male of UBC in his left proximal humerus: Anteroposterior radiograph after surgery (C) and 4 years 7 months after surgery (D). Partial healing was observed after surgery of cannulated screw.

cortical thickness $(\geqq 2 \mathrm{~mm},<2 \mathrm{~mm})$ were analyzed for occurrence of fracture at presentation. In addition to these factors, fractures at presentation, history of biopsy, treatment (observation, surgery), and surgery (placement of cannulated screw or not) (single, multiple) were evaluated for healing of UBC. UBCs in humerus were classified into active phase (juxtaposed to the cartilaginous growth plate) or latent phase (migrating away and separating from the growth plate) [4], and the phase (active, latent) was evaluated for healing. $P$-values of $<0.05$ were considered to indicate significance.

This study was approved by Nagoya university ethics committee in November, 2012, and the registration number was 2012-0202. After obtaining a waiver of patient informed consent requirements from our institutional review board, we conducted a retrospective review from clinical records.

\section{Results}

Sixty of 155 patients had pathological fracture at presentation. In univariate analysis, cyst in long bone $(p<0.001)$, diameter more than $5 \mathrm{~cm}(p<0.001)$, multilocular cyst $(p<0.001)$, ballooning of bone $(p<0.001)$, cortical thickness less than $2 \mathrm{~mm}(p<0.001)$, age less than 20 years $(p=0.001)$, and male sex $(p=0.006)$ were associated with a significantly increased incidence of pathological fractures at presentation (Table 3). Forty-three of 55 cases (78\%) in humerus, 10 of 35 cases (29\%) in femur, 2 of 10 cases $(20 \%)$ in pelvis, 1 of 5 cases (20\%) in tibia, 1 of 5 cases (20\%) in fibula, 1 of 41 cases (2\%) in calcaneus, and 2 of 4 cases in other bones had pathological fracture at presentation. In univariate analysis, UBC in humerus (43/55; 78\%) had significantly more fractures than UBC at any other site (17/ $100 ; 17 \%)(p<0.001)$, whereas UBC in calcaneus $(1 / 41 ; 2 \%)$ had significantly less fracture than at any other site $(59 / 114$; 
Table 3 Univariate and multivariate analysis of pathological fracture $(n=155)$

\begin{tabular}{|c|c|c|c|c|}
\hline \multirow[t]{2}{*}{ Clinical factors } & \multirow[t]{2}{*}{ No. of fractures (\%) } & \multirow{2}{*}{$\begin{array}{c}\text { Univariate analysis } \\
\qquad \text {-value }^{\mathrm{a}}\end{array}$} & \multicolumn{2}{|c|}{ Multivariate analysis } \\
\hline & & & $P$-value ${ }^{\mathrm{b}}$ & $\operatorname{OR}^{c}\left(95 \% \mathrm{Cl}^{\mathrm{d}}\right)$ \\
\hline \multicolumn{5}{|l|}{ Sex } \\
\hline Male & 47/101 (47\%) & \multirow{2}{*}{$p=0.006$} & \multirow{2}{*}{$p=0.013$} & \multirow{2}{*}{$3.13(1.27-7.68)$} \\
\hline Female & 13/54 (24\%) & & & \\
\hline \multicolumn{5}{|l|}{ Age, years } \\
\hline$<20$ & $53 / 114(46 \%)$ & \multirow{2}{*}{$p=0.001$} & \multirow{2}{*}{ n.s. } & \multirow{2}{*}{-} \\
\hline$\geqq 20$ & $7 / 41(17 \%)$ & & & \\
\hline \multicolumn{5}{|l|}{ Site } \\
\hline Long bone & $55 / 100$ (55\%) & \multirow{2}{*}{$p<0.001$} & \multirow{2}{*}{$p=0.012$} & \multirow{2}{*}{$4.33(1.39-13.54$} \\
\hline Others & $5 / 55(9 \%)$ & & & \\
\hline \multicolumn{5}{|l|}{ Size, $\mathrm{cm}$} \\
\hline$\geqq 5$ & $37 / 66(56 \%)$ & \multirow{2}{*}{$p<0.001$} & \multirow{2}{*}{ n.s. } & \\
\hline$<5$ & $23 / 89(26 \%)$ & & & \\
\hline \multicolumn{5}{|l|}{ Multilocular } \\
\hline Yes & 39/66 (59\%) & \multirow{2}{*}{$p<0.001$} & \multirow{2}{*}{$p=0.040$} & \multirow{2}{*}{$2.45(1.04-5.76)$} \\
\hline No & 21/89 (24\%) & & & \\
\hline \multicolumn{5}{|l|}{ Ballooning } \\
\hline Yes & 49/79 (62\%) & \multirow{2}{*}{$p<0.001$} & \multirow{2}{*}{$p=0.011$} & \multirow{2}{*}{$3.32(1.31-8.37)$} \\
\hline No & $11 / 76(14 \%)$ & & & \\
\hline \multicolumn{5}{|l|}{ Cortex } \\
\hline$<2 \mathrm{~mm}$ & $52 / 94(55 \%)$ & \multirow{2}{*}{$p<0.001$} & \multirow{2}{*}{$p=0.017$} & \multirow{2}{*}{$3.36(1.24-9.13)$} \\
\hline$\geqq 2 \mathrm{~mm}$ & $8 / 61(13 \%)$ & & & \\
\hline
\end{tabular}

${ }^{a}$ chi-square test and Fisher's exact test. ${ }^{b}$ multiple logistic regression. OR' ${ }^{c}$, odds ratio. $\mathrm{Cl}^{\mathrm{d}}$, confidence interval.

$52 \%)(p<0.001)$. In multivariate analysis, ballooning of bone $(p=0.011)$, cyst in long bone $(p=0.012)$, male sex $(p=0.013)$, cortical thickness less than $2 \mathrm{~mm}(p=0.017)$, and multilocular cyst $(p=0.040)$ were significant risk factors for pathological fractures at presentation (Table 3). One patient with femoral neck UBC developed avascular necrosis after a displaced pathological fracture, and was treated by curved intertrochanteric varus osteotomy.

Healing of UBC was less observed in the patients subjected to watchful waiting $(23 / 77 ; 30 \%)$ than in operated patients $(53 / 64 ; 83 \%)$ at the last follow up $(p<0.001)$. In observed patients, fracture at presentation $(p=0.004)$, multilocular cyst $(p=0.010)$, ballooning of bone $(p=$ $0.015)$, and history of biopsy $(p=0.019)$ were significantly associated with good healing of UBC at the last follow up in univariate analysis (Table 4). Half of the patients $(14 / 28$ patients) with fracture at presentation and $57 \%$ of patients (8/14 patients) after biopsy showed healing with observation alone at the last follow-up. Five of these 28 patients were biopsied after fractures, with 4 of them showing healing at the last follow up. Multivariate analysis showed that fracture at presentation $(p=0.004)$ and history of biopsy $(p=0.013)$ were independent factors for good healing in observed patients (Table 4).
Healing of UBC was observed in 26 of 35 patients (74\%) after operation with cannulated screw, 12 of 12 patients (100\%) with curettage and graft, 3 of 3 patients $(100 \%)$ with curettage, 2 of 3 patients (67\%) with drilling, and 10 of 11 patients (91\%) with other methods at the last follow up. There was a statistical significant difference between cannulated screw and other treatment methods for healing of UBC $(p=0.046)$ (Table 5). UBC had healed in 40 of 50 patients (80\%) after single surgery and in 13 of 14 patients (93\%) after multiple surgeries ( $p=$ $0.244)$. In multivariate analysis for healing of UBC in humerus, latent phase UBC $(p=0.011)$ and treatment with surgery $(p=0.011)$ were significantly associated with good healing of UBC (Table 6). In patients with UBC in humerus, 3 of 10 patients with active phase and 12 of 21 patients with latent phase were healed at last follow up with observation $(p=0.152)$, and 6 of 11 patients with active phase and 12 of 12 patients with latent phase were healed after surgery $(p=0.014)$.

\section{Discussion}

This is one of the largest studies to have focused on $\mathrm{UBC}$ in the trunk and extremities. There have been some clinical series of UBC including some with over 
Table 4 Univariate and multivariate analysis for healing of UBC in observed patients $(n=77)$

\begin{tabular}{|c|c|c|c|c|}
\hline \multirow[t]{2}{*}{ Clinical factors } & \multirow[t]{2}{*}{ No. of healing (\%) } & \multirow{2}{*}{$\begin{array}{l}\text { Univariate analysis } \\
\qquad P \text {-value }{ }^{\mathrm{a}}\end{array}$} & \multicolumn{2}{|c|}{ Multivariate analysis } \\
\hline & & & $P$-value ${ }^{\mathrm{b}}$ & $\mathrm{OR}^{\mathrm{c}}\left(95 \% \mathrm{Cl}^{\mathrm{d}}\right)$ \\
\hline \multicolumn{5}{|l|}{ Sex } \\
\hline Male & 18/49 (37\%) & \multirow{2}{*}{$p=0.082$} & & \\
\hline Female & $5 / 28(18 \%)$ & & & \\
\hline \multicolumn{5}{|l|}{ Age, years } \\
\hline$<20$ & 19/53 (36\%) & \multirow{2}{*}{$p=0.088$} & & \\
\hline$\geqq 20$ & $4 / 24(17 \%)$ & & & \\
\hline \multicolumn{5}{|l|}{ Site } \\
\hline Long bone & $17 / 50(34 \%)$ & \multirow{2}{*}{$p=0.281$} & & \\
\hline Others & $6 / 27(22 \%)$ & & & \\
\hline \multicolumn{5}{|l|}{ Size, $\mathrm{cm}$} \\
\hline$\geqq 5$ & $12 / 31(39 \%)$ & \multirow{2}{*}{$p=0.164$} & & \\
\hline$<5$ & $11 / 46(24 \%)$ & & & \\
\hline \multicolumn{5}{|l|}{ Multilocular } \\
\hline Yes & 13/27 (48\%) & \multirow{2}{*}{$p=0.010$} & \multirow{2}{*}{ n.s. } & \\
\hline No & $10 / 50(20 \%)$ & & & \\
\hline \multicolumn{5}{|l|}{ Ballooning } \\
\hline Yes & 15/34 (44\%) & \multirow{2}{*}{$p=0.015$} & \multirow{2}{*}{ n.s. } & \\
\hline No & 8/43 (19\%) & & & \\
\hline \multicolumn{5}{|l|}{ Cortex } \\
\hline$<2 \mathrm{~mm}$ & 17/44 (39\%) & \multirow{2}{*}{$p=0.052$} & & \\
\hline$\geqq 2 \mathrm{~mm}$ & 6/33 (18\%) & & & \\
\hline Pathological fracture a & & & & \\
\hline Yes & $14 / 28(50 \%)$ & & $n=0 \cap 04$ & 5014721621 \\
\hline No & $9 / 49(18 \%)$ & $p=0.004$ & $p=0.004$ & $3.31(1.73-10.31)$ \\
\hline Hisory of biopsy & & & & \\
\hline Yes & $8 / 14(57 \%)$ & & & \\
\hline No & $15 / 63(24 \%)$ & $p=0.019$ & $p=0.013$ & $5.47(1.44-20 . / 6)$ \\
\hline
\end{tabular}

100 patients $[1,14,15]$, but only a few large studies have been reported within the past quarter of a century [16].

Previous reports described some clinical factors that are associated with an increased incidence of pathological fracture with UBC. Radiographic features such as cyst index (area of the cyst/diaphysis diameter ${ }^{2}$ ) [5,7], percentage of bone occupied by the cyst in the transverse plane [6], and cortical thickness [7] were reported as prognostic factors of fractures with UBC. Another report showed that active phase UBC in an upper limb was at greater risk of fracture [8]. In our study, multivariate analysis revealed that ballooning of bone, cyst in long bone, male sex, thin cortical thickness and multilocular cyst had a significant impact on increasing the incidence of pathological fractures at presentation. There was a possibility that high activity in young males influenced the high occurrence of pathological fracture in our study. The high occurrence of fracture in ballooning bone, cysts in long bone and thin cortical thickness may reflect the vulnerability of ballooning bone and mechanical weakness of long bone, and multilocular UBC were usually observed in wildly spread cysts. In UBCs of humerus, latent phase significantly promoted good healing of UBC, with this finding consistent with previous reports [11]. These cysts at high risk for pathological fractures are clinically problematic and should be considered for surgery or careful observation.

Most of the pathological fractures were not displaced, were treated with immobilization, and healed without other complications, whereas one patient with femoral neck UBC in this study developed avascular necrosis after displaced pathological fracture. Some case reports have described avascular necrosis after pathological fracture in femoral neck UBC, and concluded that every 
Table 5 Univariate analysis for healing of UBC after surgery $(n=64)$

\begin{tabular}{|c|c|c|}
\hline Clinical factors & No. of healing (\%) & $\begin{array}{c}\text { Univariate analysis } \\
\qquad \text {-value }^{\mathrm{a}}\end{array}$ \\
\hline \multicolumn{3}{|l|}{ Sex } \\
\hline Male & $33 / 41(80 \%)$ & \multirow{2}{*}{$p=0.386$} \\
\hline Female & $20 / 23(87 \%)$ & \\
\hline \multicolumn{3}{|l|}{ Age, years } \\
\hline$<20$ & 42/53 (79\%) & \multirow{2}{*}{$p=0.103$} \\
\hline$\geqq 20$ & $11 / 11(100 \%)$ & \\
\hline \multicolumn{3}{|l|}{ Site } \\
\hline Long bone & $36 / 45(80 \%)$ & \multirow{2}{*}{$p=0.281$} \\
\hline Others & 17/19 (89\%) & \\
\hline \multicolumn{3}{|l|}{ Size, $\mathrm{cm}$} \\
\hline$\geqq 5$ & 28/32 (88\%) & \multirow{2}{*}{$p=0.320$} \\
\hline$<5$ & $25 / 32(78 \%)$ & \\
\hline \multicolumn{3}{|l|}{ Multilocular } \\
\hline Yes & 29/35 (83\%) & \multirow{2}{*}{$p=0.623$} \\
\hline No & $24 / 29(83 \%)$ & \\
\hline \multicolumn{3}{|l|}{ Ballooning } \\
\hline Yes & $32 / 40(80 \%)$ & \multirow{2}{*}{$p=0.341$} \\
\hline No & $21 / 24(88 \%)$ & \\
\hline \multicolumn{3}{|l|}{ Cortex } \\
\hline$<2 \mathrm{~mm}$ & $36 / 45(80 \%)$ & \multirow{2}{*}{$p=0.299$} \\
\hline$\geqq 2 \mathrm{~mm}$ & $17 / 19(89 \%)$ & \\
\hline \multicolumn{3}{|l|}{ Pathological fracture at first visit } \\
\hline Yes & $26 / 31(84 \%)$ & \multirow{2}{*}{$p=0.828$} \\
\hline No & $27 / 33(82 \%)$ & \\
\hline \multicolumn{3}{|l|}{ Hisory of biopsy } \\
\hline Yes & $13 / 16(81 \%)$ & \multirow{2}{*}{$p=0.558$} \\
\hline No & 40/48 (83\%) & \\
\hline \multicolumn{3}{|l|}{ Surgery } \\
\hline Placement of cannulated screw & $26 / 35(74 \%)$ & \multirow{2}{*}{$p=0.046$} \\
\hline Others & 27/29 (93\%) & \\
\hline
\end{tabular}

${ }^{\mathrm{a}}$ chi-square test and Fisher's exact test.

effort should be made to prevent pathologic fractures because of the vascular supply to the upper femoral epiphysis in childhood and the reported incidence of avascular necrosis even with undisplaced fracture $[12,13]$.

The clinical factors associated with good UBC healing have been reported as fracture [10], small cyst volume [10], rising cyst index [5], and long distance from the growth plate $[4,11]$. In our study, multivariate analysis showed that fracture at presentation and history of biopsy were good prognostic factors for healing of UBC in patients under observation, being partially consistent with the findings of previous reports. An especially interesting finding in our study was the effect of biopsy on healing of UBC. The diagnosis of UBC is usually not difficult, but some other lesions, especially in aged patients and patients after fracture, should be considered in the differential diagnosis such as primary or secondary $\mathrm{ABC}$, fibrous dysplasia, non-ossifying fibroma, giant cell tumor, and osteosarcoma. A previous report showed that fractured UBCs frequently appear complicated on MR imaging, with heterogeneous fluid signals and regions of nodular and thick peripheral enhancement related to pathologic fracture and early healing [17]. Because some UBCs did not show typical imaging findings on X-ray or magnetic resonance imaging, we performed biopsy in $22 \%$ of patients. In these patients, $57 \%$ of UBC patients with watchful waiting had healed after biopsy, and a 
Table 6 Univariate analysis for healing of UBC in humerus $(n=54)$

\begin{tabular}{|c|c|c|c|c|}
\hline \multirow[t]{2}{*}{ Clinical factors } & \multirow[t]{2}{*}{ No. of healing (\%) } & \multirow{2}{*}{$\begin{array}{c}\text { Univariate analysis } \\
\qquad \text {-value }^{\mathrm{a}}\end{array}$} & \multicolumn{2}{|c|}{ Multivariate analysis } \\
\hline & & & $P$-value ${ }^{\mathrm{b}}$ & $\operatorname{OR}^{c}\left(95 \% \mathrm{Cl}^{\mathrm{d}}\right)$ \\
\hline \multicolumn{5}{|l|}{ Sex } \\
\hline Male & $26 / 42(62 \%)$ & \multirow{2}{*}{$p=0.539$} & & \multirow{2}{*}{ - } \\
\hline Female & $7 / 12(58 \%)$ & & & \\
\hline \multicolumn{5}{|l|}{ Age, years } \\
\hline$<20$ & 29/46 (63\%) & \multirow{2}{*}{$p=0.374$} & & \multirow{2}{*}{ - } \\
\hline$\geqq 20$ & $4 / 8(50 \%)$ & & & \\
\hline \multicolumn{5}{|l|}{ Phase } \\
\hline Active & $9 / 21(43 \%)$ & \multirow{2}{*}{$p=0.028$} & \multirow{2}{*}{$p=0.011$} & \multirow{2}{*}{$0.16(0.04-0.65)$} \\
\hline Latent & 24/33 (73\%) & & & \\
\hline \multicolumn{5}{|l|}{ Size, $\mathrm{cm}$} \\
\hline$\geqq 5$ & 19/31 (61\%) & \multirow{2}{*}{$p=0.975$} & & \\
\hline$<5$ & $14 / 23(61 \%)$ & & & \\
\hline \multicolumn{5}{|l|}{ Multilocular } \\
\hline Yes & $21 / 34(62 \%)$ & \multirow{2}{*}{$p=0.898$} & & \multirow{2}{*}{ - } \\
\hline No & $12 / 20(60 \%)$ & & & \\
\hline \multicolumn{5}{|l|}{ Ballooning } \\
\hline Yes & 28/41 (68\%) & \multirow{2}{*}{$p=0.055$} & & \\
\hline No & $5 / 13(38 \%)$ & & & \\
\hline \multicolumn{5}{|l|}{ Cortex } \\
\hline$<2 \mathrm{~mm}$ & 28/46 (61\%) & \multirow{2}{*}{$p=0.626$} & & - \\
\hline$\geqq 2 \mathrm{~mm}$ & $5 / 8(63 \%)$ & & & \\
\hline Pathological fracture at & & & & \\
\hline Yes & $27 / 43(63 \%)$ & $n-0123$ & & - \\
\hline No & $6 / 11(55 \%)$ & $p=0.433$ & & \\
\hline Hisory of biopsy & & & & \\
\hline Yes & $8 / 12(67 \%)$ & $n=0 \Delta 61$ & & - \\
\hline No & $25 / 42(60 \%)$ & $p=0.401$ & & \\
\hline Treatments & & & & \\
\hline Surgery & 18/23 (78\%) & & & \\
\hline Observation & $15 / 31(48 \%)$ & $p=0.026$ & $p=0.011$ & $6.90(1.57-30.33)$ \\
\hline
\end{tabular}

${ }^{a}$ chi-square test and Fisher's exact test. ${ }^{b}$ multiple logistic regression. $\mathrm{OR}^{\mathrm{c}}$, odds ratio. $\mathrm{Cl}^{\mathrm{d}}$, confidence interval.

history of biopsy was noted to be an independent favorable factor for healing in observed patients.

In UBCs of humerus, latent phase significantly promoted good healing of UBC, with this finding consistent with previous reports [11]. All cysts with latent phase were healed after surgery, and cysts with latent phase at high risk for pathological fractures may be good indication for surgery.

Ahn et al. and Garceau et al. reported that $8 \%$ and $15 \%$ of UBCs healed after fractures, respectively [6,9], whereas in our study, 50\% of UBCs after fracture healed without surgical treatment. Five of 28 patients with watchful waiting after fractures were biopsied, 4 of whom showed healing at the last follow up. The high biopsy rate in our study may have accounted for the high healing rate after fracture in the observed patients. The effect of pathological fracture and biopsy may be similar to that of making multiple holes in surgery [3].

In this study, UBC healing was defined as healing of the cyst area over $50 \%$ on X-ray at the last follow up. Many of UBC healings were observed in heterogeneous areas (Figure 1D), and the complete healing rate has been reported as being relatively low [18]. Since complete healing is not necessary for prevention of pathological fracture, we defined cyst healing over $50 \%$ as cyst healing. 
Although various treatment methods have been proposed for UBC [15], less invasive methods such as cannulation, steroid injection, flexible intramedullary nailing, and endoscopic surgery have come to be preferred [19-22]. Elastic intramedullary nailing is the method of choice of treatment of unicameral bone cysts in children, it was reported to have the twofold benefits of continuous cyst decompression, and early immediate stability to the involved bone segment, which permits early mobilization and return to the normal activities of the preteen patients [22]. In our study, healing of UBC was observed in $74 \%$ of patients with cannulation and in 93\% after other operations, while treatment with cannulated screw showed a lower healing rate than other surgical methods in univariate analysis. But this may not indicate the inferiority of this method for UBC. Tsuchiya et al. showed a higher success rate of $88 \%$ after treatment with cannulated screw [19]. The primary purpose of treatment in $\mathrm{UBC}$ is the prevention of pathological fracture, and the less marked invasiveness of cannulation is consistent with this purpose.

There were some limitations in our study. The first was the lack of data concerning the recurrence of UBC after treatment. We analyzed the final results of UBC healing at the last follow up after a median period of 28.7 (range 6.039.7) months, and did not take any recurrence of UBC into consideration. The recurrence rate of UBC was reported as $30 \%$ at the proximal end of the humerus and $17 \%$ at the proximal end of the femur [14]. Another report showed that the overall recurrence rate after surgery was $39 \%$ in a long follow up [23], although there was a further possibility of UBC relapse after the final last follow up. The second limitation was the evaluation of UBC healing in patients with multiple surgeries. Healing of UBC was observed in 53 of 64 cases treated surgically, although 13 of 53 patients healed only after multiple surgeries. We did not evaluate the effect of additional surgeries on UBC healing. Third, there was an apparent selection bias between treatment groups. The healing rates were $30 \%$ and $83 \%$ with observation and surgery, respectively, but a simple comparison was difficult to make because the two groups were not homogeneous. Finally, this study included various types of UBC, both pediatric and adult cases, long bone and others, and observed and operated cases. Especially this study included 41 of 155 cases of adult cases, but most of these were young adult and some of adult cases were pathologically diagnosed.

\section{Conclusions}

In conclusion, ballooning of bone, cyst in long bone, male sex, thin cortical thickness and multilocular cyst were significant adverse prognostic factors for pathological fractures, whereas fracture at presentation and history of biopsy were favorable prognostic factors for healing of UBC in patients under observation. These clinical factors may be useful for deciding treatment in patients with UBC. A history of mechanical disruption of UBC such as fracture and biopsy seems to be good indication for watchful waiting, but patients with some poor prognostic factors of fractures or with UBC in the femur should be treated with surgery.

\section{Competing interests}

All the authors declare that they have no financial and personal relationship with other people or organization that could potentially and inappropriately influence (bias) their work and conclusion.

\section{Authors' contributions}

$\mathrm{HU}, \mathrm{KH}, \mathrm{NI}, \mathrm{YN}$ were involved in the conception and design of the study; ST $\mathrm{HS}, \mathrm{KY}, \mathrm{YY}, \mathrm{EK}, \mathrm{EA}$, and NF in acquisition of data; and $\mathrm{HU}$ and $\mathrm{KH}$ in analysis of data. HU drafted the article, and all authors edited and revised it for important intellectual content. HU, ST and YN take responsibility for the integrity of the work as a whole, from inception to finished article. All authors approved the finish version to be published.

\section{Acknowledgment}

We thank Miss Eri Ishihara for secretarial assistance and Hiroatsu Nakashima for assistance of data collection.

\section{Funding sources}

One or more of the authors (H.U.) has received research funding from the Ministry of Education, Culture, Sports, Science and Technology of Japan [Grant-in-Aid 24791533 for Scientific Research (C)].

\section{Author details}

${ }^{1}$ Department of Orthopedic Surgery, Nagoya University Graduate School and School of Medicine, 65 Tsurumai, Showa-ku, Nagoya, Aichi 466-8550, Japan. ${ }^{2}$ Department of Orthopedic Surgery, Aichi Cancer Center Aichi Hospital, 18 Kuriyado, Kake-machi, Okazaki, Aichi 444-0011, Japan. ${ }^{3}$ Department of Orthopedic Surgery, Aichi Cancer Center Hospital, 1-1 Kanokoden, Chikusa-ku, Nagoya, Aichi 464-8681, Japan. ${ }^{4}$ Department of Orthopedic Surgery, Nagoya Memorial Hospital, 4-305 Hirabari, Tenpaku-ku, Nagoya, Aichi 468-8520, Japan.

Received: 16 January 2014 Accepted: 9 May 2014

Published: 17 May 2014

\section{References}

1. Campanacci M, Capanna R, Picci P: Unicameral and aneurysmal bone cysts. Clin Orthop Relat Res 1986, 204:25-36.

2. Oliveira AM, Perez-Atayde AR, Inwards CY, Medeiros F, Derr V, Hsi BL, Gebhardt MC, Rosenberg AE, Fletcher JA: USP6 and CDH11 oncogenes identify the neoplastic cell in primary aneurysmal bone cysts and are absent in so-called secondary aneurysmal bone cysts. Am J Pathol 2004, 165(5):1773-1780.

3. Chigira M, Maehara S, Arita S, Udagawa E: The aetiology and treatment of simple bone cysts. J Bone Joint Surg Br 1983, 65(5):633-637.

4. Neer CS, Francis KC, Johnston AD, Kiernan HA Jr: Current concepts on the treatment of solitary unicameral bone cyst. Clin Orthop Relat Res 1973, 97:40-51.

5. Kaelin AJ, MacEwen GD: Unicameral bone cysts. Natural history and the risk of fracture. Int Orthop 1989, 13(4):275-282.

6. Ahn JI, Park JS: Pathological fractures secondary to unicameral bone cysts. Int Orthop 1994, 18(1):20-22.

7. Zamzam MM, Abak AA, Bakarman KA, Al-Jassir FF, Khoshhal Kl, Zamzami MM: Efficacy of aspiration and autogenous bone marrow injection in the treatment of simple bone cysts. Int Orthop 2009, 33(5):1353-1358.

8. Tey IK, Mahadev A, Lim KB, Lee EH, Nathan SS: Active unicameral bone cysts in the upper limb are at greater risk of fracture. J Orthop Surg 2009, 17(2):157-160

9. Garceau GJ, Gregory CF: Solitary unicameral bone cyst. J Bone Joint Surg Am 1954, 36(A:2):267-280.

10. Wright JG, Yandow S, Donaldson S, Marley L, Simple Bone Cyst Trial G: $A$ randomized clinical trial comparing intralesional bone marrow and steroid injections for simple bone cysts. J Bone Joint Surg Am 2008, 90(4):722-730 
11. Haidar SG, Culliford DJ, Gent ED, Clarke NM: Distance from the growth plate and Its relation to the outcome of unicameral bone cyst treatment. J Child Orthop 2011, 5(2):151-156.

12. Khermosh O, Weissman SL: Coxa vara, avascular necrosis and osteochondritis dissecans complicating solitary bone cysts of the proximal femur. Clin Orthop Relat Res 1977, 126:143-146.

13. Taneda H, Azuma H: Avascular necrosis of the femoral epiphysis complicating a minimally displaced fracture of solitary bone cyst of the neck of the femur in a child. A case report. Clin Orthop Relat Res 1994, 304:172-175.

14. Neer CS 2nd, Francis KC, Marcove RC, Terz J, Carbonara PN: Treatment of unicameral bone cyst. A follow-up study of one hundred seventy-five cases. J Bone Joint Surg Am 1966, 48(4):731-745.

15. Spence KF, Sell KW, Brown RH: Solitary bone cyst: treatment with freezedried cancellous bone allograft. A study of one hundred seventy-seven cases. J Bone Joint Surg Am 1969, 51(1):87-96.

16. Glowacki M, Ignys-O'Byrne A, Ignys I, Mankowski P, Melzer P: Evaluation of volume and solitary bone cyst remodeling using conventional radiological examination. Skelet Radiol 2010, 39(3):251-259.

17. Margau R, Babyn P, Cole W, Smith C, Lee F: MR imaging of simple bone cysts in children: not so simple. Pediatr Radiol 2000, 30(8):551-557.

18. HashemiNejad A, Cole WG: Incomplete healing of simple bone cysts after steroid injections. J Bone Joint Surg Br 1997, 79B(5):727-730.

19. Tsuchiya H, Abdel-Wanis ME, Uehara K, Tomita K, Takagi Y, Yasutake H: Cannulation of simple bone cysts. J Bone Joint Surg (Br) 2002, 84(2):245-248

20. Capanna R, Dal Monte A, Gitelis S, Campanacci M: The natural history of unicameral bone cyst after steroid injection. Clin Orthop Relat Res 1982, 166:204-211.

21. Innami K, Takao M, Miyamoto W, Abe S, Nishi H, Matsushita T: Endoscopic surgery for young athletes with symptomatic unicameral bone cyst of the calcaneus. Am J Sports Med 2011, 39(3):575-581.

22. Pogorelic Z, Furlan D, Biocic M, Mestrovic J, Juric I, Todoric D: Titanium intramedullary nailing for treatment of simple bone cysts of the long bones in children. Scott Med J 2010, 55(3):35-38.

23. Hagmann S, Eichhorn F, Moradi B, Gotterbarm T, Dreher T, Lehner B, Zeifang F: Mid- and long-term clinical results of surgical therapy in unicameral bone cysts. BMC Musculoskelet Disord 2011, 12:281.

doi:10.1186/1471-2474-15-159

Cite this article as: Urakawa et al:: Clinical factors affecting pathological

fracture and healing of unicameral bone cysts. BMC Musculoskeletal Disorders 2014 15:159.

\section{Submit your next manuscript to BioMed Central and take full advantage of:}

- Convenient online submission

- Thorough peer review

- No space constraints or color figure charges

- Immediate publication on acceptance

- Inclusion in PubMed, CAS, Scopus and Google Scholar

- Research which is freely available for redistribution 